\title{
A IMPORTÂNCIA DO ESTÁGIO SUPERVISIONADO CLÍNICO PARA A ATUAÇÃO DO PSICOPEDAGOGO
}

\author{
M.S.A. REGO, M.M.L. PONTES \\ Universidade do Estado do Rio Grande do Norte \\ socorro_ok4@hotmail.com
}

Artigo submetido em 01/01/2017 e aceito em 05/12/2019

DOI: $10.15628 /$ holos.2019.5515

\section{RESUMO}

A presente pesquisa teve o propósito de identificar de que forma a experiência do estágio supervisionado clínico contribui para a atuação do psicopedagogo, bem como relatar a experiência de estágio vivenciada no curso de pós-graduação, psicopedagogia institucional e clínica. É importante mencionar que a psicopedagogia busca no contexto institucional e clínico entender como se dá o processo de aprendizagem humana e a partir de uma atuação eficiente do psicopedagogo, com métodos adequados, a detectar e superar as dificuldades e/ou bloqueios que são barreiras no desenvolvimento de aprendizagem dos aprendentes. A pesquisa é de caráter qualitativo, descritivo e bibliográfico respaldando-se em
Chamat (2004; 2008), Pimenta (2012), Porto (2009a; 2009b), Sampaio (2009), Weiss (2008), um trabalho monográfico de Gonçalves (2007). A relevância desta pesquisa se deu a partir dos resultados obtidos, em que pudemos observar que é no estágio supervisionado que o futuro profissional pode adquirir uma variedade de conhecimentos visto que é nesse momento que acontece a práxis, relação teoria-prática. O estudo detectou ainda que a atuação do psicopedagogo no estágio é importante para que este possa saber lidar com a criança e com a dificuldade diagnosticada durante o acompanhamento psicopedagógico.

PALAVRAS-CHAVE: Estágio Supervisionado, Psicopedagogo, Aprendizagem.

\section{THE IMPORTANCE OF THE CLINICAL SUPERVISED INTERNSHIP FOR THE WORK OF THE EDUCATIONAL PSYCHOLOGIST}

\begin{abstract}
The present research aimed to identify how the experience of the clinical supervised internship contributes to the work of the educational psychologist, as well as reporting the internship experience in the postgraduate program, institutional and clinical psychopedagogy. It is important to mention that the psychopedagogy aims at the institutional and clinical context to understand how the human learning process occurs and from an efficient performance of the educational psychologist, with adequate methods, to detect and overcome the difficulties and/or blockages that are barriers in the learning development of the learners. The research is qualitative, descriptive, and
\end{abstract}

bibliographic endorsed by Chamat (2004; 2008), Pimenta (2012), Porto (2009a; 2009b), Sampaio (2009), Weiss (2008), and one final paper by Gonçalves (2007). The relevance of this research was obtained from the final results, in which we could observe that it is during the supervised internship that the future professional can acquire a variety of knowledges since it is at this moment that happens the praxis, the theory-practice connection. The study also identified that the work of the educational psychologist in the internship is important to learn how to deal with children and with the difficulties diagnosed during psychopedagogical supervision.

KEYWORDS: Supervised Internship, Educational Psychologist, Learning. 


\section{INTRODUÇÃO}

A pesquisa intitulada "A importância do estágio supervisionado clínico para a atuação do psicopedagogo" teve como propósito apresentar como o psicopedagogo pode adquirir conhecimentos para a sua atuação profissional a partir da prática do estágio supervisionado, tendo como foco a questão problema: Como o estágio supervisionado clínico contribui para a atuação do psicopedagogo?

A psicopedagogia clínica busca na sua prática a partir de sessões diagnósticas compreender, detectar os problemas de aprendizagem e com um trabalho eficaz tentar de forma curativa sanar tais problemas, proporcionando aos aprendentes alívio e continuidade nos estudos, não tendo assim dificuldades no processo de aprendizagem.

Diante disso, o trabalho vislumbrou como objetivo identificar de que forma a experiência do estágio supervisionado clínico contribui para a atuação do psicopedagogo, uma vez que é no estágio que o profissional adquire conhecimentos para a sua prática. Para alcançarmos os objetivos propostos buscamos o caminho metodológico qualitativo, descritivo e bibliográfico respaldando-se em Chamat (2004; 2008), Pimenta (2012), Porto (2009a; 2009b), Sampaio (2009), Weiss (2008), um trabalho monográfico de Gonçalves (2007) que contribuíram com discussões relevantes para a temática estudada.

Sendo assim, é importante entender a contribuição da psicopedagogia clínica para o contexto escolar como uma ferramenta que propicia o acompanhamento e intervenção dos problemas e dificuldades de aprendizagem. Por isso, o estágio impulsiona uma experiência ajudando ao profissional aprendente a adquirir conhecimentos práticos e como lidar com a situação estudada a partir das teorias aprendidas no curso.

A pesquisa teve dois momentos distintos, sendo o primeiro o embasamento teórico para que seja possível fazer uma discussão da temática e, posteriormente, a descrição de como foi a experiência do estágio supervisionado, realizado na instituição escolar, tendo como objeto de estudo apenas uma criança.

Dessa maneira, a escolha do tema em questão se deu a partir da experiência vivenciada no estágio supervisionado clínico. O qual foi realizado no período de junho a julho de 2015 em uma escola da cidade de Pau dos Ferros-RN, em que foi feito o acompanhamento com uma criança que apresentava dificuldade de aprendizagem. No qual despertou interesse pessoal em divulgar a experiência do estágio como forma de contribuir para a propagação da profissão.

O presente trabalho está organizado da seguinte forma: na seção 2 apresentamos a metodologia utilizada, já na seção 3 discutimos o percurso histórico da psicopedagogia, fazendo uma breve explanação do seu surgimento. Na seção 4 abordamos os campos de atuação do psicopedagogo no âmbito clínico e educacional, e como se dá a atuação do psicopedagogo, falando da sua importância para a detecção dos problemas de aprendizagem.

Na seção 5 refletimos sobre a práxis do estágio supervisionado, debatendo a relevância do estágio e as etapas do diagnóstico psicopedagógico. Na seção 6 expusemos o relato de experiência 
do estágio, mostrando como foi esse momento. E por fim, apresentamos nossas considerações finais apontando a relevância do trabalho e os resultados alcançados.

\title{
2 METODOLOGIA
}

A metodologia utilizada para a realização da pesquisa foi de caráter qualitativo, descritivo e embasada na pesquisa bibliográfica respaldando-se em Chamat (2004; 2008), Pimenta (2012), Porto (2009a; 2009b), Sampaio (2009), Weiss (2008), um trabalho monográfico de Gonçalves (2007) que contribuíram com discussões relevantes para a temática estudada.

Sendo assim, a pesquisa teve dois momentos distintos, sendo o primeiro o embasamento teórico para que fosse possível fazer uma discussão da temática e, posteriormente, a descrição de como foi a experiência do estágio supervisionado realizado na instituição escolar com uma criança que apresentava dificuldade de aprendizagem.

\section{O PERCURSO HISTÓRICO DA PSICOPEDAGOGIA}

A psicopedagogia percorreu um contexto histórico diversificado, ela surgiu inicialmente na Europa no século XIX sendo voltada para a realização de um processo de reeducação no intuito de resolver os problemas de aprendizagem de origem orgânica em que o médico solucionaria tais problemas.

$\mathrm{Na}$ Europa em 1946 surgiram Centros Psicopedagógicos, um deles foi fundado por George Mauco na França para atender crianças com problemas comportamentais e escolares, para isso havia a integração de várias áreas do conhecimento, como pedagogia, psicologia e psicanálise que davam sua contribuição por meio de um acompanhamento psicopedagógico para entender as dificuldades das crianças. Assim:

\begin{abstract}
A psicopedagogia tem como objeto de estudo a aprendizagem humana, que surgiu de uma demanda - as dificuldades de aprendizagem, colocada em um espaço pouco explorado, situado além dos limites da Pedagogia e da Psicologia. (...) Como essas duas áreas de conhecimento não são suficientes para formar o corpo teórico da Psicopedagogia, recorre-se a outras áreas [...]. (Porto, 2009a, p.07).
\end{abstract}

A corrente europeia influenciou a Argentina e os Estados Unidos em que neste os problemas de aprendizagem eram decorridos de problema de saúde, por isso a criança necessitava de um atendimento especializado para tratar as dificuldades escolares, contudo na Argentina houve uma distinção, pois buscava uma articulação de desenvolver um trabalho de reeducação para tentar solucionar os problemas de aprendizagem escolar.

Para tanto, foi na Argentina que em 1956 surgiu o curso de graduação em psicopedagogia na Universidade de Buenos Aires, atraindo a atenção de profissionais que possuíam outras formações acadêmicas e buscavam tal curso para aprimorá-las e melhor acompanhar o desenvolvimento educacional dos alunos que apresentam déficits escolares.

Assim, alguns psicopedagogos argentinos como Jorge Visca, Sara Pain, Alícia Fernández e Marina Muller contribuíram de forma significativa para que a psicopedagogia fosse implantada no 
Brasil como uma área de conhecimento que ajudaria aos profissionais do contexto escolar entenderem o modo de como lidar com os problemas de aprendizagem (Gonçalves, 2007).

Na década de 60 surge então a psicopedagogia no Brasil, sendo voltada exclusivamente para sanar os problemas de aprendizagem de forma reeducativa relacionados a disjunção neurológica (transtorno de hiperatividade e déficit de atenção-TDH/A) que causavam o fracasso escolar de muitas crianças.

Contudo, a psicopedagogia no Brasil diferencia-se da desenvolvida na Argentina, uma vez que neste país é permitida a aplicação de testes que os psicólogos aplicam durante o acompanhamento, enquanto que no Brasil só há a permissão para a aplicação de tais testes para os psicopedagogos que tenham formação em psicologia. Desse modo:

[...] no Brasil, vem sofrendo, tornando-se um obstáculo para o psicopedagogo iniciante, pois ao profissional dessa área é vedado o uso de instrumentos psicológicos. Aqui, cabe ressaltar que os instrumentos psicológicos pertencem a uma outra área e que a escassa formação do psicopedagogo não the permite estar de posse de subsídios ou recursos teóricos para tal empreendimento. (Chamat, 2004, p.29).

Dessa forma, a psicopedagogia é uma área de conhecimento nova, que tem como objeto de estudo o processo de aprendizagem humana e se apoia em outras ciências, como psicologia, psicanálise, pedagogia, filosofia, neurologia, medicina, linguística de forma interdisciplinar em que cada uma dará sua contribuição para entender o desenvolvimento humano.

A primeira experiência brasileira com a psicopedagogia foi em 1958 na cidade de GuanabaraRJ em que era oferecido um atendimento de orientação psicopedagógica da escola experimental do Instituto de Estudos e Pesquisas Educacionais do Ministério da Educação - INEP, objetivando proporcionar uma boa relação entre professor e aluno (Gonçalves, 2007).

Na cidade de São Paulo surge o primeiro curso de pós-graduação em psicopedagogia no Instituto Sedes Sapientiae, promovendo mudanças significativas constituindo a origem da Associação Estadual de Psicopedagogia de São Paulo-AEP, que buscava detectar as causas dos problemas de aprendizagem dos alunos.

A Associação Estadual de Psicopedagogia de São Paulo foi criada por um grupo de profissionais que
já atuava na área, acabava de fazer sua formação em psicopedagogia no Instituto Sedes Sapientiae
e sentia a necessidade de ser reconhecido como categoria profissional, consciente de seu papel na
comunidade. Tendo a Associação se expandido [...] faz com que sintamos a necessidade de efetivar
a proposta da criação da Associação Brasileira de Psicopedagogia. (Rubinstein, 1987 apud
Gonçalves, 2007, p. 22).

Dessa forma, a psicopedagogia ganha avanços e reconhecimento tendo uma associação que garante aos profissionais os direitos necessários para a sua atuação na sociedade, um desses direitos foi a criação do Código de Ética, o qual explicita a natureza do trabalho psicopedagógico, que é institucional e clínico, o campo de atuação dos profissionais que pode ser na educação e na saúde, deveres destes profissionais e relações com profissionais de outras áreas (Associação Brasileira de Psicopedagogia, 2011).

Nesse sentido, a psicopedagogia tem dois campos de atuação, institucional e clínica, que "Tanto na clínica quanto na instituição, o psicopedagogo atua intervindo como mediador entre o 
sujeito e sua história traumática, ou seja, a história que lhe causou a dificuldade de aprender" (Porto, 2009a, p.91). Dessa forma, contribuem para a expansão dessa área de conhecimento no âmbito escolar e fora dele para solucionar as dificuldades de aprendizagem.

A psicopedagogia institucional acontece na escola, hospital, empresa sendo "[...] uma área de estudo nova, voltada para o atendimento de sujeitos que apresentam problemas de aprendizagem" (Porto, 2009b, p. 107), tendo a função preventiva buscando detectar os possíveis problemas no processo de ensino-aprendizagem, nas relações interpessoais utilizando para isso estratégias de intervenção.

Já a psicopedagogia clínica é realizada em centros de atendimento ou clínicas psicopedagógicas tendo como objetivo "[...] identificar as causas dos bloqueios que se apresentam nos sujeitos com dificuldades de aprendizagem [...]" (Sampaio, 2009, p.17). Sendo assim, é função da psicopedagogia clínica curar os problemas num processo de investigação das causas dos sintomas que acarretam as dificuldades escolares para uma possível intervenção através de um diagnóstico realizado por etapas até chegar em um prognóstico, investigando assim os fatores orgânicos, emocionais, cognitivos, pedagógicos, a vida do sujeito.

Portanto, a psicopedagogia percorreu um caminho de lutas e conquistas para chegar ao que é hoje, uma área de conhecimento que se utiliza das demais ciências para estudar, compreender o processo de aprendizagem humana, dando sua contribuição nas instituições escolares, empresariais, hospitalares e também em centros clínicos que ajudam na realização do tratamento psicopedagógico dos problemas de aprendizagem.

\section{A ATUAÇÃO DO PSICOPEDAGOGO CLÍNICO}

O psicopedagogo clínico irá atuar de forma curativa e preventiva para "[...] focalizar a problemática dentro do contexto causa/sintoma e atuar sobre eles. Deve planejar sua atuação desde o contato telefônico. Este, muitas vezes, fornece dados de como estão as relações vinculares familiares" (Chamat, 2008, p. 26), buscando compreender no paciente seus aspectos sociais, afetivos, emocionais, orgânicos e pedagógicos na tentativa de sanar as dificuldades que interferem na aprendizagem.

Para isso terá o diagnóstico psicopedagógico realizado em sessões, possibilitando "[...] a investigação e a intervenção para que se compreenda o significado, a causa e a modalidade de aprendizagem do sujeito, com o intuito de sanar as dificuldades" (Porto, 2009a, p.91). Nesse sentido, o acompanhamento tendo a aplicação de provas e testes é possível obter as informações necessárias sobre o paciente, as causas e o problema, podendo dessa forma, escolher o melhor tratamento para ser feito em busca de sanar o problema.

Então, pode-se perceber que no diagnóstico é necessário levar em conta toda a história de vida do paciente, seus aspectos afetivos, emocionais, cognitivos, familiares e sociais para melhor utilizar os instrumentos e procedimentos que conduzirão no processo de intervenção, servindo de alicerce para que o psicopedagogo possa realizar um trabalho eficaz. 
Nessa perspectiva, quando o psicopedagogo realizar o diagnóstico terá como fazer a síntese diagnóstica, que é o resultado das hipóteses levantadas em todas as sessões realizadas com o sujeito em que irá formular uma única hipótese a partir de todos os dados obtidos no diagnóstico, ou seja, é neste momento que o profissional terá que saber a causa principal do problema de aprendizagem da criança.

O psicopedagogo tendo realizado todo o processo de acompanhamento com o sujeito nas sessões terá na síntese a resposta para a queixa que foi levantada pela família no momento do primeiro contato e que motivou a procura de um profissional para tratar o problema. Sabendo disso, ele realiza a devolutiva que acontece tanto com a família quanto com o paciente, é o encerramento do diagnóstico em que o psicopedagogo apresenta os resultados obtidos durante o processo de investigação.

O trabalho do psicopedagogo é interdisciplinar envolvendo profissionais de outras áreas de conhecimento, como psicólogos, neurologistas, fonoaudiólogos, psicolinguísticas, psicanalistas, dentre outros, que juntos podem realizar um trabalho eficaz contribuindo para o prognóstico do paciente dando informações relevantes para o estudo do problema detectado.

Sendo assim, o psicopedagogo para atuar profissionalmente de forma eficiente, é necessário que possua algumas habilidades sendo elas, criatividade, habilidade técnica, interdisciplinaridade e construa sua identidade por meio da práxis psicopedagógica, uma vez que:

O psicopedagogo pode ser criativo e desenvolver atividades que possibilitem observar os aspectos da inteligência e da projeção e, se achar que os testes psicológicos são importantíssimos para concluir um diagnóstico, poderá encaminhar o cliente a um psicólogo a fim de que ele realize uma avaliação psicológica, efetivando um trabalho multidisciplinar. (Porto, 2009a, p. 94).

Portanto, o psicopedagogo tem um papel de suma importância tanto no campo institucional e clínico, uma vez que investiga os problemas de aprendizagem e de relação interpessoal podendo diagnosticar, orientar e atender através de um tratamento psicopedagógico, propiciando qualidade no desempenho de aprendizagem da criança com dificuldades escolares.

\section{A PRÁXIS NO ESTÁGIO SUPERVISIONADO E ETAPAS DO DIAGNÓSTICO}

O estágio supervisionado clínico para os alunos de pós-graduação em psicopedagogia possibilita a aproximação com a realidade que irão atuar, pois segundo Pimenta (2012) “[...] o estágio curricular é atividade teórica de conhecimento, fundamentação, diálogo e intervenção na realidade, esta sim, objeto da práxis." (p. 45). Então, o estágio é o momento oportuno de conhecer formas de como trabalhar e detectar a causa dos problemas de aprendizagem, havendo assim uma reflexão das teorias estudadas no curso e aplicando-as na prática psicopedagógica.

Desse modo, o estágio é assegurado pela Associação Brasileira de Psicopedagogia como um exercício direto in loco, isto é, momento em que o aluno em formação poderá exercer na prática os conhecimentos adquiridos no curso, tendo um professor orientador supervisionando sua atuação, ajudando no planejamento das atividades a serem desenvolvidas e como proceder em cada situação encontrada na realidade investigada. Pois: 
A atuação supervisionada é uma atividade intrinsecamente articulada com a prática e com as atividades de trabalho acadêmico. Nesse sentido deve ser previsto tempo suficiente para a realização das atividades de planejamento, avaliação e intervenção nos diferentes espaços de atuação do psicopedagogo. [...] A atuação supervisionada deve contar com o acompanhamento de um professor supervisor, com experiência comprovada na área da Psicopedagogia, responsável direto pelas atividades. A elaboração de registros próprios, de prontuários e de relatórios deve ser orientada por princípios éticos fazendo parte da rotina do aluno. (Associação Brasileira de Psicopedagogia, 2013).

É notório perceber que o estágio é relevante para os futuros profissionais da psicopedagogia, uma vez que contribui para que o estagiário se aproxime da realidade com a qual irá desenvolver seu trabalho de intervenção e, além disso, relacionar teoria e prática, estas são mecanismos essenciais para que este desenvolva um trabalho de qualidade.

Assim sendo, o campo do estágio pode ser um momento imprescindível para a realização de pesquisa, propiciando aos estagiários ampliar e analisar os problemas de aprendizagem que estejam investigando a partir de aprofundamento sobre a problemática diagnosticada, buscando para isso projetos de intervenção que tentarão amenizar as causas dos problemas e impulsionando uma educação eficiente para os aprendentes que apresentam déficits de aprendizagem.

A pesquisa no estágio como método de formação de futuros professores, se traduz, de um lado, na mobilização de pesquisas que permitam a ampliação e análise dos contextos onde os estágios se realizam; por outro lado, e em especial, se traduz na possibilidade de os estagiários desenvolverem postura e habilidades de pesquisador a partir das situações de estágio, elaborando projetos que lhes permitam ao mesmo tempo compreender e problematizar as situações que observam [...]. (Pimenta, 2012, p. 46).

Diante disso, para que o estágio seja feito de forma eficiente deve-se seguir etapas que auxiliarão no processo do diagnóstico, sendo estas realizadas com sessões psicopedagógicas com o sujeito e tendo duração de uma hora, sendo elas: Contato com a família, Anamnese, Entrevista Operativa Centrada na Aprendizagem - EOCA, Provas Operatórias, Técnicas projetivas, Prognóstico e Devolução, em que a cada final da sessão pode ser feito um levantamento de hipótese sobre a criança e o seu problema (Sampaio, 2009).

Estas etapas podem ser realizadas da forma como o psicopedagogo ver melhor, não sendo obrigatória seguir a sequência que foi colocada acima, pois há teóricos, como Sampaio (2009) na área psicopedagógica que preferem a realização da anamnese após as provas e testes, uma vez que o profissional fazendo no início do diagnóstico terá uma preconcepção de ideias sobre o sujeito ao qual investigará, porém há teóricos que aconselham que a anamnese seja no início.

O primeiro contato que o psicopedagogo faz com a família é na entrevista contratual, em que é apresentado aos familiares que o diagnóstico será realizado em sessões para a identificação da problemática. É neste momento que é feita a queixa por parte da família a respeito da dificuldade que a criança vem apresentando na escola, esse primeiro contato com os familiares tem os objetivos de:

[...] compreensão da queixa nas dimensões familiares e escolar, a captação das relações e expectativas familiares centradas na aprendizagem escolar, a expectativa em relação à atuação do terapeuta, a aceitação e o engajamento do paciente e seus pais no processo diagnóstico, a realização do contrato e do enquadramento de forma familiar e o esclarecimento do que é um diagnóstico psicopedagógico. (Weiss, 2008, p. 52, grifo do autor). 
Diante do que foi exposto por Weiss (2008) é notório observar que é de suma importância o contato com a família, pois é a partir desse contato que se pode saber o motivo pelo qual há a procura do profissional para a resolução do problema. Na conversa deve haver confiança dos pais no profissional e este esclarecer como será o processo de acompanhamento com a criança.

A anamnese é uma entrevista realizada com os pais ou responsáveis com o objetivo de obter informações sobre a história de vida do sujeito investigado desde sua concepção até o momento atual, coletando dados também do seu desenvolvimento físico, cognitivo, emocional, psicológico e escolar, para que possa saber o caminho metodológico adequado.

$\mathrm{Na}$ anamnese busca-se todas as informações significativas sobre o desenvolvimento geral do indivíduo levantando dados de sua evolução como pessoa, história clínica, primeiras aprendizagens escolares ou informais, comportamento e relacionamento familiar dentre outros que são importantes para o diagnóstico, ela pode ser feita no início ou final do diagnóstico dependerá da estratégia do profissional (Chamat, 2004).

A Entrevista Operativa Centrada na Aprendizagem - EOCA é a primeira sessão feita com a criança tendo o intuito de observar o que o sujeito sabe fazer e o que aprendeu a fazer, seguindo uma consigna proposta por Visca (1987), que é a criança mostrar o que sabe fazer, o que a ensinaram a fazer e o que aprendeu a fazer. Com isso será possível observar o nível de conhecimento, modalidade de defesa, conduta, ansiedades, operatividade, destrezas e analisar a criança em três aspectos: temática, dinâmica e produto.

A EOCA deve ser feita de forma espontânea e lúdica para que a criança se sinta bem, confortável tendo confiança no profissional, realizando as atividades propostas por ele sem medo e que não encare essas atividades como tarefas escolares, que esse momento seja como uma coisa nova para a criança. Desse modo:

Penso que na primeira sessão deve-se evitar transformar as propostas em tarefas escolares, uma vez que o que levou o paciente a nos procurar foi um tipo de dificuldade escolar, e assim é coerente que ele no primeiro dia não queira mostrar seu 'ponto fraco'. [...] pode-se chegar ao verdadeiro nível pedagógico ao longo de várias sessões: algumas transcorrendo de forma lúdica e outras formalizadas com propostas e questões dentro de objetivos específicos. (Weis, 2008, p. 57).

Diante do exposto é notório perceber que a EOCA nos permite enfatizar na aprendizagem da criança buscando o que ela aprendeu durante o processo de ensino-aprendizagem e do que aprendeu fora do contexto escolar a partir das vivências, experiências adquiridas no meio social.

Outro momento é a hora do jogo, que é uma técnica desenvolvida por Sara Paín (1985), que tem como objetivo proporcionar a criança que está sendo acompanhada expressar seus conhecimentos, imaginação, criatividade, linguagens e imitação diante dos objetos e jogos disponibilizados. Na sessão lúdica a criança pode brincar de forma espontânea, ela é quem escolhe do que quer brincar para que possa ser possível avaliar seu processo de aprendizagem por meio dos jogos (Chamat, 2004).

Dessa forma, a utilização de situações lúdicas na sessão deixa a criança mais espontânea para revelar dados importantes ao psicopedagogo sobre os aspectos afetivos, sociais, emocionais, 
exploração ao novo, a relação interpessoal que contribuem bastante à compreensão do sujeito e o levantamento de hipóteses para a continuidade do diagnóstico.

As provas operatórias têm o objetivo de verificar o nível de pensamento da criança, conhecendo o funcionamento e o desenvolvimento das funções lógicas, como o sujeito organiza suas ideias, que argumentos utiliza para responder aos questionamentos feitos pelo psicopedagogo. Pode-se fazer provas de conservação, seriação e classificação (Sampaio, 2009).

Sendo assim, estas provas contribuem de forma significativa para que o profissional possa detectar, nos momentos dos interrogatórios, se a criança organiza bem suas ideias e consegue ter uma argumentação firme que justifique seu ponto de vista a partir das contra argumentações formuladas nas diferentes provas, verificando também se o nível cognitivo corresponde a idade cronológica.

As técnicas projetivas são utilizadas para investigar os vínculos de aprendizagem que o sujeito estabelece entre família, escola e consigo mesmo num processo realizado por meio de desenhos ou relatos solicitados, sendo dessa forma um meio em que a criança poderá revelar variedades de respostas que auxiliarão no diagnóstico.

As tarefas propostas permitem uma diversidade de respostas, havendo, portanto, o livre jogo da imaginação, da fantasia, dos desejos. O princípio básico é de que a maneira do sujeito perceber, interpretar e estruturar o material ou situação reflete os aspectos fundamentais do seu psiquismo. [...] podem-se detectar, assim, obstáculos afetivos existentes nesse processo de aprendizagem de nível geral e especificamente escolar. (Weiss, 2008, p.118, grifo do autor).

Nesse sentido, é a partir dos desenhos ou relatos feitos pela criança que podemos observar a manifestação do inconsciente, das marcas deixadas pelas experiências vivenciadas para verificar as significações do ato de aprender e as relações vinculadas com a aprendizagem e as figuras ensinantes. As provas solicitadas mais comuns são: família educativa e par educativo (Sampaio, 2009).

Assim é notório perceber que as técnicas projetivas contribuem para o levantamento de novas hipóteses para o diagnóstico, propiciando ao psicopedagogo adquirir informações sobre o vínculo de aprendizagem estabelecido pela criança e observar se tal vínculo é positivo ou negativo, sendo possível saber que caminho trilhar a partir das hipóteses levantadas.

Outros mecanismos importantes no diagnóstico são os testes pedagógicos, estes utilizados nas sessões como suportes importantes para a avaliação diagnóstica, sendo "uma complementação que funciona com situações estimuladoras que provocam reações variadas, às vezes intensas, em pouco espaço de tempo". (Weiss, 2008, p. 103). Dessa forma, estes importantes mecanismos proporcionam a coleta de dados a partir da necessidade apresentada pelo sujeito investigado.

Os testes pedagógicos ajudam ao profissional a trabalhar com mais ênfase na dificuldade que a criança apresenta e que foi relatada na queixa, no momento inicial do diagnóstico e percebido durante a realização das outras sessões, impulsionando assim, uma avaliação mais específica do problema de aprendizagem.

São inúmeros os testes que o psicopedagogo pode realizar no diagnóstico, tendo aqueles relacionados a coordenação motora, lateralidade, orientação espacial, testes de sondagem de 
leitura e escrita, compreensão textual, cálculo etc., que são trabalhados dependendo da dificuldade de aprendizagem detectada na criança (Sampaio, 2009).

O psicopedagogo ao finalizar o diagnóstico da dificuldade investigada poderá fazer a síntese diagnóstica ou informe psicopedagógico, que é o resultado das hipóteses levantadas em todas as sessões realizadas com o sujeito formulando uma única hipótese a partir de todos os dados obtidos no diagnóstico, ou seja, é neste momento que o psicopedagogo terá que saber a causa principal do problema de aprendizagem da criança (Weiss, 2008).

Por fim ocorre a entrevista devolutiva que acontece tanto com a família quanto com o paciente, é o encerramento do diagnóstico em que o psicopedagogo apresenta os resultados obtidos durante o processo de investigação. É um momento de muita espera e ansiedade pelos pais e pela própria criança para saberem a causa que provoca a dificuldade de aprendizagem.

É importante que no momento da divulgação dos resultados tenha a organização de um roteiro que inicialmente aborde os aspectos cognitivos e só depois os pedagógicos, orgânicos, afetivos e sociais da criança, e não esquecendo que deve iniciar relatando os aspectos positivos da criança para que ela se sinta valorizada.

Sendo assim, após o psicopedagogo mencionar os aspectos que causam a dificuldade de aprendizagem, ele pode fazer encaminhamentos e recomendações para que a criança supere o que esteja bloqueando sua aprendizagem promovendo o tratamento com ela ou indicando para o atendimento com outros profissionais, como psicólogos, fonoaudiólogos, neurologista.

Portanto, a prática do estágio propiciada pelos cursos de pós-graduação em psicopedagogia é de suma importância para a relação de teoria-prática no contexto educacional, uma vez que a partir das sessões psicopedagógicas o estagiário tentará detectar as possíveis causas que impedem o progresso da aprendizagem das crianças.

\section{ESTÁGIO SUPERVISIONADO CLÍNICO: UM RELATO DE EXPERIÊNCIA}

O estágio supervisionado foi realizado numa escola que oferece ensino da Pré-escola ao 5o ano dos Anos Iniciais do Ensino Fundamental, nesta há crianças que apresentam problemas de aprendizagem relacionados principalmente à leitura e escrita, raciocínio lógico-matemático. Inicialmente foi feito o contato com a instituição, especialmente com a diretora para que fosse possível a realização do estágio e posteriormente o contato com a professora para liberação da criança com a dificuldade de aprendizagem.

O aluno escolhido para a realização de sessões diagnósticas estudava o 5o ano e a queixa que a professora apresentou foi relacionada aos problemas de leitura e escrita, devido não ter interesse para estudar. Logo após escolher o aluno houve o primeiro contato com os responsáveis, em que foi enviado um comunicado pedindo a presença na escola para uma conversa.

A duração do estágio foi de aproximadamente de um mês, de junho a julho de 2015, sendo feito um acompanhamento em 9 sessões psicopedagógicas duas vezes na semana com duração de uma hora. Segundo Pimenta (2012) “A obrigatoriedade legal do estágio e o cumprimento de sua respectiva carga horária nos cursos de formação [...] têm sido uma das grandes preocupações das 
instituições [...] a carga horária obrigatória (de 300 para 800 horas)". (p. 100). Com o cumprimento da carga horária do estágio foi possível realizar um trabalho produtivo.

Em cada sessão foi possível perceber que o trabalho do psicopedagogo é importante para detectar e solucionar as dificuldades de aprendizagem, trabalho esse que é feito com muito esforço e estudo, pois cada hipótese levantada, é necessário buscar teóricos que nos seus estudos discutem a forma adequada de como lidar com tal hipótese.

Nas primeiras sessões com a criança a estagiária sentiu medo e dificuldade, não sabendo que caminhos trilhar, como analisar o comportamento e gestos da criança, mas com o manual psicopedagógico de Sampaio (2009) foi possível entender como se dá de forma clara:

[...] as etapas do diagnóstico psicopedagógico clínico no intuito de tornar o entendimento do diagnóstico mais acessível e claro para estudantes de Psicopedagogia e para aqueles que já estão formados e desejam iniciar sua prática psicopedagógica, mas apresentam dificuldades em unir todas as etapas, já que as mesmas são encontradas em livros didáticos. (Sampaio, 2009, p. 15).

É notório perceber que o referido manual orienta os passos necessários a seguir em cada sessão, sendo acessível as informações e procedimentos metodológicos a serem aplicados no processo do diagnóstico. Como também a ajuda de referenciais teóricos e da orientação da professora supervisora, foi imprescindível para dar continuidade ao trabalho de forma segura e eficiente.

Para tanto, a criança quando iniciou as sessões falava pouco por ser tímida, não gostava de falar mesmo sendo questionada, mas no decorrer do trabalho sentiu confiança no profissional. Segundo Weiss (2008) "criada a relação de confiança, com mais facilidade pode a criança se engajar e assim colaborar nos momentos de testagem ou de avaliação de aspectos pedagógicos". (p.56). A partir disso foi possível colher dados importantes sobre a criança, que é inteligente, obediente, prestativa, criativa e organizada, mas é insegura, não acredita na sua capacidade.

Foi possível detectar ainda que a criança apresentava dificuldade de leitura e escrita devido à ausência de sua mãe e por não conhecer e ter contato com o pai. Essa carência afetiva de mãe e pai criou um bloqueio na aprendizagem, uma vez "a criança deseja e necessita ser amada, aceita, acolhida e ouvida para que possa despertar para a vida da curiosidade e do aprendizado" (Porto, 2009, p.26), que apesar de receber amor e carinho da avó que a cria como se fosse seu filho, a criança não sente ser amada e querida.

Observamos também que a criança só conseguia falar sobre sua vida familiar e escolar nos momentos de algumas provas e principalmente nos jogos, visto que "quando se joga, a atividade é predominantemente assimilativa, pois o sujeito deve interagir com o novo objeto [...]". (Chamat, 2004 , p. 100). Nos momentos lúdicos tinha a segurança e confiança para expressar seus sentimentos, vontades e desejos, apesar de ser tímida, nesses momentos conseguiu se expressar melhor para a psicopedagoga.

Diante de tudo que foi coletado nas sessões, em seguida foi feita a devolutiva com a avó da criança, tendo alguns encaminhamentos para aprimorar o desenvolvimento da sua aprendizagem, como: continuar tendo o acompanhamento com a psicopedagoga; a família ter paciência com o seu desenvolvimento de aprendizagem e incentivar nos estudos; ter mais contato com a mãe e se 
possível com o pai; a possibilidade de colocar em um reforço escolar para progredir na leitura e na escrita. E para a instituição de ensino foi feita também a devolutiva para que esta dificuldade que a criança enfrentava no seu processo de aprendizagem da leitura e da escrita seja sanada e a criança consiga progredir nos estudos.

A experiência do estágio com a criança que apresentava uma queixa de dificuldade de aprendizagem na leitura e escrita foi riquíssima, uma vez que detectar que o motivo foi devido a mãe estar longe de sua vivência, morando em outro lugar e não ter também contato com o pai. Isso provocou um bloqueio na sua aprendizagem, dessa forma, foi um trabalho investigativo eficiente, e, também no decorrer do diagnóstico foi possível perceber que a criança tinha uma baixa autoestima, insegurança e em seu seio familiar sempre foi taxada como aquela que não aprende. A duração do estágio de um mês na instituição de ensino com a criança contribuiu para adquirir conhecimentos para a prática psicopedagógica, auxiliando assim no trabalho investigativo.

Portanto, o estágio supervisionado foi de suma relevância para a formação da psicopedagoga que no momento estava no período de formação, pois propiciou relacionar teoriaprática no acompanhamento da criança com dificuldade de aprendizagem e tentar detectar o problema que bloqueava o seu desenvolvimento, buscando meios que pudessem ajudá-la a superar, bem como orientar a professora e a família sobre como lidar com a situação do aprendente.

\section{CONCLUSÃO}

O estudo foi bem significativo uma vez que apresentou a importância da atuação do psicopedagogo no estágio supervisionado, o qual proporcionou a construção de novos conhecimentos e foi o momento oportuno para que houvesse a práxis, relacionar teoria e prática.

Nesse sentido, conhecer e acompanhar um problema de aprendizagem apresentado por uma criança no contexto escolar e tentar descobrir a causa que impede esse sujeito de avançar é uma experiência relevante para o profissional que está em formação, e no momento de a atuação buscar conhecimentos teóricos e práticos para que possa desenvolver um trabalho excelente e de qualidade.

Sendo assim, quando o psicopedagogo realiza sessões psicopedagógicas é possível conhecer o desenvolvimento da criança nos aspectos cognitivos, sociais, emocionais, afetivos e sua história de vida pessoal e escolar, procurando por meio de situações lúdicas proporcionar uma intervenção adequada. A intervenção psicopedagógica é um excelente momento para compreender o processo de ensino-aprendizagem e buscar meios para solucionar os obstáculos que impedem as crianças de evoluírem nos estudos.

Portanto, espera-se que este estudo possa contribuir para futuras pesquisas científicas na área, que discutam a importância do estágio supervisionado para a formação e atuação do psicopedagogo almejando que este desenvolva um trabalho excelente e de qualidade tanto no contexto escolar quanto clínico visando sempre a aprendizagem dos aprendentes. 


\section{REFERÊNCIAS}

1. Associação Brasileira de Psicopedagogia. (2011). Código de ética do psicopedagogo. Recuperado de https://www.abpp.com.br/documentos_referencias_codigo_etica.html.

2. Associação Brasileira de Psicopedagogia. (2013). Diretrizes da formação de psicopedagogos no Brasil. Recuperado de https://www.abpp.com.br/documentos_referencias_diretrizes_formacao.html.

3. Chamat, L. S. J. (2004). Técnicas de diagnóstico psicopedagógico: o diagnóstico clínico na abordagem interacionista. 1a ed. São Paulo: Vetor.

4. Chamat, L. S. J. (2008). Técnicas de intervenção psicopedagógica: para dificuldades e problemas de aprendizagem. 1a ed. São Paulo: Vetor.

5. Gonçalves, L. S. (2007). Psicopedagogia: formação identidade e atuação profissional. Monografia (Especialização em educação e psicopedagogia). Faculdade de Educação, da Pontifícia Universidade Católica de Campinas, Campinas. Cap. 1, p. 12-25. Recuperado de http://bibliotecadigital.puccampinas.edu.br/services/monografias/Luciana\%20dos\%20Santos\%20Goncalves.pdf.

6. Pimenta, S. G. (2012). Estágio e docência. 7a ed. São Paulo: Cortez.

7. Porto, O. (2009a). Bases da psicopedagogia: diagnóstico e intervenção nos problemas de aprendizagem. 4 a ed. Rio de Janeiro: Wak Ed.

8. Porto, O. (2009b). Psicopedagogia institucional: teoria, prática e assessoramento psicopedagógico. 3a ed. Rio de Janeiro: Wak Ed.

9. Sampaio, S. (2009). Manual prático do diagnóstico psicopedagógico clínico. Rio de Janeiro: Waked.

10. Weiss, M. L. L. (2008). Psicopedagogia clínica: uma visão diagnóstica dos problemas de aprendizagem escolar. 13a ed. Rio de Janeiro: Lamparina. 